\title{
Slavko Osterc in Lucijan Marija Škerjanc: estetski razkol in poetsko bratstvo
}

\author{
Gregor Pompe \\ Univerza v Ljubljani \\ University of Ljubljana
}

Lucijana Marijo Škerjanca in Slavka Osterca pogosto razumemo kot antagonistični dvojec, ki naj bi v temelju zaznamoval slovensko glasbo najprej med obema vojnama, razlike med obema "šolama« - oba sta bila tudi pomembna učitelja oz. profesorja kompozicije - pa naj bi odmevale še v sodobnem času. Tako že Marijan Lipovšek izpostavlja Škerjanca kot "protipol« Ostercu, češ da sta si oba skladatelja »nasprotna do zadnjega kotička«, Dragotin Cvetko govori o tem, da je bila med Ostercem in Škerjancem »vidna napetost, gotovo zavoljo različnih umetnostnih nazorov «, ${ }^{2}$ Darja Koter trdi, da sta bila »Škerjanc kot tradicionalist in Osterc kot avantgardist [...] večna rivala ${ }^{3}$, o nasprotujočih osebnostnih in estetikah ter celo dveh »kompozicijskih šolah" pa govori tudi Katarina Bogunović Hočevar. ${ }^{4}$

Osrednje razlike je najlažje razkriti na estetski ravni, pri čemer je poenostavljeno rečeno Škerjanca moč razumeti kot tradicionalista ${ }^{5}$ in Osterca kot doslednega zagovornika novega. Svojo tradicionalistični držo Škerjanc izpostavlja zelo jasno, ko trdi, da »doslej ni bil izrabljen niti odstotek vseh

1 Marijan Lipovšek, »Naša glasbena produkcija«, Ljubljanski zvon 55, 10-11 (1935): 577.

2 Dragotin Cvetko, Osebnost skladatelja Slavka Osterca (Ljubljana: Cankarjeva založba, 1993), 117.

3 Darja Koter, Slovenska glasba. 1918-1991 (Ljubljana: Študentska založba, 2012), 143.

4 Katarina Bogunović Hočevar, »Ravnikovi glasbenoestetski nazori v kontekstu dveh kompozicijskih šol«, De musica disserenda 6, 2 (2010), 87.

5 Prim.: Monika Kartin, Simfonije Lucijana Marije Škerjanca, magistrsko delo (Ljubljana: Filozofska fakulteta, 1982), 125. 
možnih zvočnih kombinacij [in zato] ni nobene potrebe po novih tonskih sistemih «. ${ }^{6}$ Seveda pa je mogoče iti v razpiranju razlik še globlje, pri čemer je Škerjančeva tradicionalnost jasno povezana $\mathrm{z}$ njegovim osrednjim prepričanjem o subjektivnosti umetniškega ustvarjanja, ki je pripeto na močno čustvovanje in instinkt tako avtorja kot sprejemnikov. Tako je prepričan, da je "glasba individualno in množično prilagodljiva ter pripravna za ponazarjanje najrazličnejših odtenkov čustev «, ${ }^{7}$ hkrati pa je prepričljivost umetnine »funkcija notranjega zanosa, ki je preveval umetnika-ustvaritelja ob delu in čigar odsev je - bolj ali manj popolno - znal položiti v umetnino samo«. ${ }^{8}$ Umetnina nosi vse značilnosti ustvarjalnega subjekta, zato tudi sama ni objekt, ampak v resnici umetniški subjekt: ${ }^{9}$ „Edino v umetnosti možno in upravičeno geslo je iskrenost. ॥ $^{10}$ Seveda so takšnim prepričanjem Osterčevi pogledi skoraj diametralno nasprotni. V tem smislu je mogoče razumeti že njegovo nedvoumno priznanje: "Fanatično odklanjam tradicijo. «" Odmika se od romantičnega poudarjanja moči subjekta in s tem iracionalnega ter poudarja pomen racionalnega. Prepričan je, da ima »vsaka umetniška tvorba svoje intelektualno ozadje «, ${ }^{\text {I2 }}$ zato "zahtevamo intelekt pri komponistih! « ${ }^{13}$ Tako ne preseneča, da je »dostikrat namerno prezrl emocijo ${ }^{\mathrm{I} 4}$ in bil nasploh nasprotnik sentimentalizma in romantike. ${ }^{\mathrm{IS}}$

Takšne razlike v osnovni estetski drži so nato logično odmevale tudi v zasnovi glasbenega stavka, ki je pri Škerjancu slonel na tradicionalnih izhodiščih, medtem ko je Osterc zaupal raznolikim sodobnim vzpodbudam. $\mathrm{Ni}$ čudno, da je bil kot dedič 19. stoletja in moderne, Škerjanc »izrazit akordik«. ${ }^{16}$ Harmonija je zanj »konstruktivna in oblikovalna sila, brez katere bi

6 Lucijan Marija Škerjanc, »Vrednotenja«, Sodobnost 9, 2 (1933): 57.

7 Lucijan Marija Škerjanc, »Apologia musicae artis«, Sodobnost 1 (1953): 172.

8 Prav tam, 178.

9 Lucijan Marija Škerjanc, »Moji umetnostni nazori«, Sodobnost 8, 5 (1940): 204.

10 Škerjanc, »Vrednotenja«, 58.

11 Slavko Osterc cit. po Katarina Bedina, »Nazori Slavka Osterca o tradiciji v glasbi in o glasbenem nacionalizmu«, Muzikološki zbornik 3 (1967): 90.

12 Slavko Osterc, »Čustvo in razum v glasbi«, Žena 6, 4 (1935): 95.

13 Slavko Osterc, »Muzika u zemlji«, Zvuk 2, 3 (1933): 104.

14 Cvetko, Osebnost skladatelja Slavka Osterca, 185.

15 Bratko Kreft, »Spomini na Slavka Osterca in še marsikaj«, v Varia musicologica 2. Slavko Osterc, ur. Katarina Bedina (Ljubljana: Slovensko muzikološko društvo, 1995), 256.

16 Monika Kartin, »Peta simfonija Lucijana Marije Škerjanca«, Muzikološki zbornik 19 (1983): 67 . 
ostale višje formalne težnje neizpolnljive «, ${ }^{17}$ obenem pa je prepričan, da je polifonija, torej

»kombinacija več sočasnih melodij [...] bolj spekulativna tvorba kot pa neposreden izraz ustvarjalne potrebe. Dejansko ni mogoče enakovredno in enako pozorno dojemati več sočasno odvijajočih se melodij in vselej dajemo prednost eni pred drugo. ${ }^{18}$

Povsem drugačne poudarke je vnesel v svojo hierarhijo glasbenih parametrov Osterc, ki je prostodušno priznal, da

"je harmonija precej postranska zadeva, prepričan sem celo, da harmonično mnogo novega ne bo produciral ne ta ne oni. Tudi sem mnenja, da je harmonija najmanj bistven del invencije ter jo prištevam $k$ tisti neizogibni tehniki, brez katere ne more nastati nobeno mojstrsko delo. ${ }^{19}$

Osterčevo kompozicijsko snovanje sloni na linearnemu vodenju glasov, pri čemer »horizontalna misel [...] predstavlja enega od bistvenih elementov skladateljevega glasbenega mišljenja«. ${ }^{20}$ Toda Osterc sam je hierarhijo parametrov razumel še drugače:

»Vedno sem pri glasbi ritmu dajal prednost pred harmonijo in polifonijo. [...] V ritmu vidim največji kos originalnosti, [...] življenje, radost, komiko. ${ }^{21}$

To misel je najbrž potrebno brati tudi v kontekstu Škerjančevih sicer redkih, a odločnih kritik novih struj, ki jih je v slovensko glasbo vpeljeval Osterc - tako naj bi po pričevanju Lipovška v eni izmed njih zapisal, da »je ta muzika [...] prišla do edine ostale prvine, do ritma, se pravi, do bobna in bo tudi prišla na boben «, ${ }^{22}$ a vendarle si težje predstavljamo večjo razpetost, kot je veljala med skladateljema $\mathrm{v}$ dojemanju pomembnosti prvin glasbenega stavka. Zato najbrž niso odveč misli, da sta se morala sklada-

17 Škerjanc, »Apologia musicae artis«, 543.

18 Prav tam, 432.

19 Slavko Osterc, "Glavne struje sodobne glasbe in njih eksistenčna upravičenost«, Nova muzika 1 (1928): 3.

20 Andrej Rijavec, Kompozicijski stavek komornih instrumentalnih del Slavka Osterca (Ljubljana: Slovenska akademija znanosti in umetnosti,1972), 8.

21 Slavko Osterc cit. po Katarina Bedina, „Novo v mladinskih zborih Slavka Osterca«, $M u$ zikološki zbornik 11 (1975): 98.

22 Cit. po Bogunović Hočevar, »Ravnikovi glasbenoestetski nazori v kontekstu dveh kompozicijskih šol«, 89 . 
telja močno razlikovati tudi $\mathrm{v}$ osebnostnem pogledu in ne le $\mathrm{v}$ estetskih prepričanjih, kar nenazadnje potrjuje tudi njuna svetovnonazorska orientacija. Medtem ko je bil Osterc »izrazito v levo usmerjen intelektuale ${ }^{23}{ }^{23}$ in se je leta 1940 znašel med ustanovitelji Društva prijateljev Sovjetske zveze, ${ }^{24}$ pa Škerjanc ni imel tako jasno izdelanih politično-nazorskih stališč, a se je znal predvsem zelo dobro prilagoditi vsem spremembam oblasti, tako stari jugoslovanski s kantato Ujedinjenje, po nekaterih navedbah tudi italijanski fašistični med okupacijo ter v povojnih časih, ${ }^{25}$ ko ga je rešilo predvsem visoko mnenje, ki ga je imel o njegovi glasbi glavni kulturni usmerjevalec Josip Vidmar.

Škerjanc je tako predvsem po drugi svetovni vojni postal pomemben »igralec« na slovenski glasbeni sceni, kar priča njegova dolgoletna profesura na Akademiji za glasbo, članstvo v Akademiji znanosti in umetnosti ter upravništvo Slovenske filharmonije. Številne generacije skladateljev so šle skozi njegovo kompozicijsko šolo in čeprav ni bil posebej predan univerzitetni učitelj, ${ }^{26}$ je s svojo estetsko mislijo vendarle zaznamoval številne skladatelje, medtem ko je bil pred vojno kot učitelj na konservatoriju in srednji šoli Glasbene akademije pomemben tudi Osterc, ki si je s svojo jasno mislijo in prepričljivostjo kmalu priboril četo soborcev in sledilcev v novo glas$b o$, toda pomembneje je, da si je prek članstva v Mednarodnem združenju za sodobno glasbo izboril tudi pomembno mesto na mednarodni skladateljski sceni, kar ni mogoče trditi o Škerjancu.

Toda kljub vsem tem očitnim razlikam sta si bila Škerjanc in Osterc na poetološki ravni vendarle bistveno bolj podobna, kot bi si lahko mislili. Njuna osnovna prepričanja so bila res močno vsaksebi, toda ko sta se do njih dokopala, zanimivo oba okoli leta 1927 (Osterc se takrat vrne s svojih študijev v Pragi, Škerjanc pa doživi svojo najbolj radikalno sodobno fazo, po kateri se »vrne« v bolj utečene tire tradicionalnega izraza), sta trdno vztrajala v svojih kompozicijskih izhodiščih, ki sta jih mestoma celo šablonizirala v lahko prepoznavne vzorce, ki so omogočali precej bogato produkcijo, kakršne slovenska glasba, če izvzamemo nekoliko starejšega Emila Adamiča, praktično ni poznala - Škerjanc je v vojnem času napisal štiri od svojih petih simfonij $(1931,1940,1942,1943,1944)$, pet godalnih kvarte-

23 Danilo Pokorn, "Slavko Osterc. Prispevek za biografijo«, Muzikološki zbornik 5 (1969): 91.

24 Prav tam.

25 Ivan Klemenčič, Slovenski skladatelji akademiki (Ljubljana: Slovenska akademija znanosti in umetnosti, 2003), 47.

26 Jurij Snoj, Portret skladatelja Janeza Matičiča (Ljubljana: Slovenska matica, 2012), 91. 
tov, nato pa poleg dveh širokopoteznih kantat (Ujedinjenje, 1936, Sonetni ve$n e c, 1949)$ ob razvejanem komornem in klavirskem opusu še celo vrsto koncertov - dva za violino $(1927,1944)$ in po enega za klavir (1940), violončelo (1947), harfo (1954), fagot (1956), klarinet (1958), violo (1959) in flavto (1962) -, medtem ko je Osterc snoval operni opus (Iz komične opere, 1928, Krog s kredo, 1929, Saloma, 1929, Dandin v vicah, 1930, Medea, 1930), številna komorna dela (sonate za violo in klavir, saksofon in klavir, violončelo in klavir), suite in klavirske kompozicije. Škerjanc je plodovitost celo posebej izpostavil kot kvaliteto izstopajočih skladateljev, ki jih ne odlikuje

"samo kakovost del, temveč tudi izredna plodnost, ki jim ni dovoljevala daljših odmorov. [...] To edino jim je tudi omogočilo, da so se povzpeli iznad sorojakov«, ${ }^{27}$

delavnost in hitro ustvarjanje pa je izpostavljal tudi Osterc, ki se na posameznostih »ni zaustavljal, ne brusil zapisanih idej $\aleph^{28}$ in je celo zapovedoval: "Delajmo in študirajmo brez počitka, da nas čas ne prehiti! «" ${ }^{29}$

Tudi njun kompozicijski »jezik« ni povsem osebno izviren, temveč vedno nabran in povzet po vabečih in izstopajočih tujih zgledih, hkrati pa v svoji izpopolnitvi tudi ni estetsko radikaliziran. Tako je Škerjanc kot osemnajstletnik stopil s koncertom svojih samospevov na slovensko glasbeno sceno kot tipični predstavnik moderne, razpete med izrazno estetiko 19. stoletja in kromatične harmonske premike 2o. stoletja, ki jih je nato pobarval še z impresionističnimi barvnimi izmiki. To je ostala osnova njegovega kompozicijskega jezika tudi v tridesetih letih, torej ko je končal vsa svoja šolanja v tujini in ko se je estetsko ustalil po krajši epizodi bolj eksperimentalno-ekspresionističnih poizkusov, ki jih lahko razberemo iz skladb nastalih v letih 1926 in 1927. Toda Škerjanc vendarle ni enostransko zavrnil sodobnih tokov, ki se jim je povsem približal s svojim enostavčnim Koncertom $z a$ violino in orkester (1927), temveč je premišljeno sprejemal nove vplive ter se $s$ tem nekako skušal postavljati ob bok Ostercu, ki se je prav v tem času vrnil iz študija v Pragi. Tako ne moremo spregledati, da je v mnoga dela iz tridesetih let Škerjanc prevzel neoklasicistične in neobaročne elemente: Preludij, arija in finale za godala (1933) prinaša neobaročno monotematsko motoričnost in kontrapunktično razpredanje, ki spominja na Hindemit-

27 Lucijan Marija Škerjanc, »Nezanimivost slovenske glasbe«, Sodobnost 8, 9 (1940): 398.

28 Katarina Bedina, »O glasbeni poetiki in prozi Slavka Osterca«, Muzikološki zbornik 25 (1989): 12. 
ha, medtem ko je Suita $v$ starem slogu (1934) zasnovana kot nekakšen concerto grosso, v katerem je mogoče godalni kvartet razumeti kot concertino, ki agira proti celotni godalni skupini kot ripieno, obsežni sonati za violončelo (1935) in violo (1936) pa bi zaradi nizanja baročnih form lahko razumeli kot posvetilo Bachovim partitam. Lahko bi celo trdili, da je $\mathrm{z}$ vsakim letom in $\mathrm{z}$ vsakim novim slogovnim impulzom Škerjančev opus postajal bolj eklektičen, kar pomeni, da je vendarle dvomil, da je preizkušal, vendar vedno previdno, tako da se je novih slogov in tehnik lotil šele takrat, ko so se zdele že "udomačene«, preizkušene in takorekoč »klasične«, kar velja tudi za dodekafonijo, s katero se je preizkušal $\mathrm{v}$ poznih petdesetih letih.

Na prvi pogled se zdi, da je bil Osterc mnogo manj "previden« kot Škerjanc in zavezanem vsemu novemu. Res se je iz študija v Pragi vrnil pod vtisom takrat najnovejših struj: neobaroka, neoklasicizma, nove stvarnosti, poznal je tudi ekspresionizem druge dunajske šole. Toda kljub temu, da je bil Osterc strasten in glasen zagovornik atonikalne in atematične glasbe, da se je postavljal zoper programsko glasbo in tonsko slikanje ter opozarjal na preživelost dur-molovega tonskega sistema, ${ }^{30}$ je bil hkrati prepričan, da »tradicija ni ovira pri ustvarjanju novih vrednot, ampak pripomoček «, ${ }^{31}$ zato ne preseneča ugotovitev Andreja Rijavca, da se ni "nikoli popolnoma odpovedal tradicionalnim funkcijskim harmonskim odnosom «. ${ }^{32}$ Tako lahko Osterčevo osnovno vodilo razumemo podobno kot pri Škerjancu v nekakšnem povzemajočem smislu, v njegovem delu je razvidna »svojevrstna zmes takratnih glasbenih poetik « ${ }^{33}$ od Busonija prek Stravinskega in Hindemitha do druge dunajske šole, torej cela pahljača, ki razpira precej raznolike estetske poudarke, Rijavec pa govori celo o »slogovnem trikotniku«, razpetem med neoklasicizem, ekspresionizem in novo stvarnost. ${ }^{34}$ Tako je Osterc postavljal pod vprašaj tradicionalno zvrstno mrežo, predvsem s svojimi uspelimi deli za komorne zasedbe, a je hkrati vendarle ustvaril sonate, godalne kvartete, klavirski trio in pihalni trio, bil je proti programski glasbi, a ustvaril operni opus, se navidez ni zanimal za harmonijo, a je vendarle izhajal iz funkcijskih odnosov, ki jih je največkrat zakril

30 Katarina Bedina, »K vprašanju o kompozicijskih nazorih Slavka Osterca«, Muzikološki zbornik 4 (1968): 114 in 116.

31 Slavko Osterc, »Gledališki pregled. Opera. Matija Bravničar: Pohujšanje v dolini šentflorjanski«, Ljubljanski zvon 50, 6 (1930): 377.

32 Andrej Rijavec, »K vprašanju tonalnosti in vertikale v skladbah Slavka Osterca«, Muzikološki zbornik 6 (1970): 39.

33 Bedina, "O glasbeni poetiki in prozi «, 9 .

34 Andrej Rijavec, "Slavko Osterc - an expressionist?«, Muzikološki zbornik 20 (1984): 53 . 
s harmonsko tujimi toni (priključene sekunde), povsem dosleden pa ni bil tudi v atematskosti. Vse to pomeni, da je podobno kot Škerjanc izbiral in ni bil do konca slepo zvest modnim trendom.

V tem pogledu sta si bila Škerjanc in Osterc podobna, imela sta najbrž tudi skupnega vzornika, Stravinskega, kar kaže predvsem Škerjančev omenjeni prvi Koncert za violino z gosto orkestracijo, ki na mnogih mestih izkazuje prvenstveno vlogo orkestrskih barvnih tekstur, česar se je moral skladatelj naučiti iz partiture Ognjena ptiča, medtem ko je Osterc sam priznal, da ga je »ravno Petruška pripeljal v tabor hipermoderne «. ${ }^{35}$ Navdušenje do Stravinskega pa sta Škerjanc in Osterc delila tudi s starejšo generacijo slovenskih skladatelj, o čemer priča navdušeno poročilo Antona Lajovica iz Festivala slovanske glasbe v Zagrebu, v katerem je izrazito pohvalil Stravinskega, ${ }^{36} \mathrm{kar}$ pomeni, da sta Škerjanc in Osterc ohranjala vez s starejšo generacijo. Seveda pa je šel Osterc tudi korak dlje, ko je izpostavljal kot edinega nekompromisnega skladatelja svojega časa Schönberga, kateremu je ob bok postavil tudi svojega učitelja Hábo, ${ }^{37}$ in se v tem pogledu jasno odlepil od generacij Novih akordov. Toda kljub takšnemu navduševanju nad delom druge dunajske šole, je bil Osterčev odnos do dodekafonije precej soroden Škerjančevemu. Tako Škerjanc v Sedmih dvanajsttonskih fragmentih (1958) in Treh skladbah za violino in klavir (1959) dvanajsttonske vrste uporablja v smislu tematskega gradiva - je nekaj namigov na inverzije in rakove obrate, toda Škerjanc ne prevzema sistema $\mathrm{v}$ celoti in obravnava vrste kot melodije, pri čemer se izogiba gostemu kontrapunktu ali zahtevnejšim izpeljavam. Osterc se je z dodekafonijo spoprijel že prej, sredi tridesetih leti, vendar podobno kot Škerjanc ni sprejel celotne Schönbergove sistematike, temveč le idejo nizanja različnih dvanajsttonskih zaporedij, katerega rezultat je popolna kromatičnost, kot je to razvidno iz skladb Mouvement symphonique (1936), Fantaisie chromatique (1940), Mati (1940) in Six petites morceaux (1940).

Še bolj pomembno kot zgornje stične točke pa je izpostaviti, da sta oba skladatelja nekatere izmed svojih postopkov kmalu šablonizirala, da nista več v temelju premišljala svojih estetskih in kompozicijsko-tehničnih izhodišč, temveč sta se zavezala predvsem širitvi svojih opusov in izpolnjevanja žanrskih »lukenj«, ki so še pestile slovensko glasbo.

35 Slavko Osterc, »Muzika u zemlji. Ljubljana«, Zvuk 3, 6 (1935): 229.

36 Primož Kuret, Umetnik in družba (Ljubljana: Državna založba Slovenije, 1988), 121. Lajovic Stravinskega ni imel zgolj za vodilnega ruskega skladatelja, temveč za najpomembnejšega svetovnega avtorja (prav tam, 168).

37 Ivan Klemenčič, »Slavko Osterc med neoklasicizmom in ekspresionizmom«, Muzikološki zbornik 31 (1995): 13 . 
Eno izmed tipičnih Škerjančevih šablon, skorajda škerjančevski topos bi lahko poimenovali »trepetajoča predstavitev večne melodije«. Skladatelj najprej zariše harmonsko okolje $\mathrm{z}$ značilnimi nerazvezanimi štirizvoki, ki so pogosto orkestracijsko ali inštrumentalno razgibani (tremolo v godalih, razloženi akordi v klavirju), čez njih pa se oglasi dolgo razpeta melodična linija. Takšno teksturo uporabi Škerjanc že v prvem izmed svojih Sedmih nokturnov (1935), ko klavirska figuracija združuje dva štirizvoka, nad takšno harmonsko osnovo pa se napenja blodeča melodična misel, sestavljena iz fragmentarnih vzgibov, zelo podobno pa je zasnovana tudi Lirična bagatela (1941), v kateri je le nekoliko drugače domišljena ritmična podoba trepetajoče akordske spremljave, nad katero se podobno sestavlja dolga melodična misel. Le nekoliko drugačna sta primera iz Četrtega in Petega godalnega kvarteta, kjer akordska spremljava ni značilno »trepetajoča«, pa vendar je nad akorde razpeta daljša melodična misel, ki črpa iz kratkih motivičnih drobcev, ki se združujejo v nekakšno »večno « melodijo - v začetku Četrtega godalnega kvarteta je takšna spremljava še večinoma homofona, iz melodičnega glasu je jasno razvidno motivično delo, medtem ko je $\mathrm{v}$ začetku drugega stavka Petega godalnega kvarteta tekstura bolj polifono razgibana, melodični glas pa je z izjemo sekvenčnega niza zasnovan bolj rapsodično.

Osterčeve šablone so bile bolj jasno povezane s sprejemanjem žanrskih obrazcev - tako v njegovih skladbah pogosto srečamo passacaglie, kanone, atonikalne fuge, korale in koračnice, pri čemer sta bolj zanimiva zadnja, "čista" glasbena žanra, katerih značilnosti niso povezane s kompozicijsko tehniko. Posebej v povezavi s koralom bi lahko govorili o Osterčevem tipu korala, o nekakšnem »koralu sekund«. Skladatelj je prevzel idejo enakomernega počasnega melodičnega gibanja $\mathrm{v}$ majhnih intervalnih korakih iz protestantskega korala, podobno je posneta tudi ideja popolne homofonije, le da je Osterc akorde pogosto močno obložil z dodanimi sekundami, ki zakrivajo funkcijske zveze in dajejo občutek disonantnih trkov. Najbolj »čiste« primere takšnih »koralov sekund « lahko razpoznamo v četrti izmed skladateljevih Bagatel (1933), v zadnji izmed Štirih miniatur (1938) za klavir, Koralu in fugi (1942), $\mathrm{v} »$ Pravljici in resnici o svetovnem miru « iz zbirke Pravliice ter Klavirskemu triu (1939), ki je zasnovan kot niz med seboj povezanih epizod, med katerimi je poslednja zasnovana kot koral. Takšen koralni idiom je Osterc uporabil tudi v simfoničnih delih - tako se že drugi stavek Koncerta za orkester (1932) prične z značilnim koralom, »Toccata« iz Štirih simfoničnih skladb (1939) se zaključuje z odsekom »Maestoso«, v katerem lahko prepoznamo sledi koralne polifonije, zelo podobno zasnovani odseki 

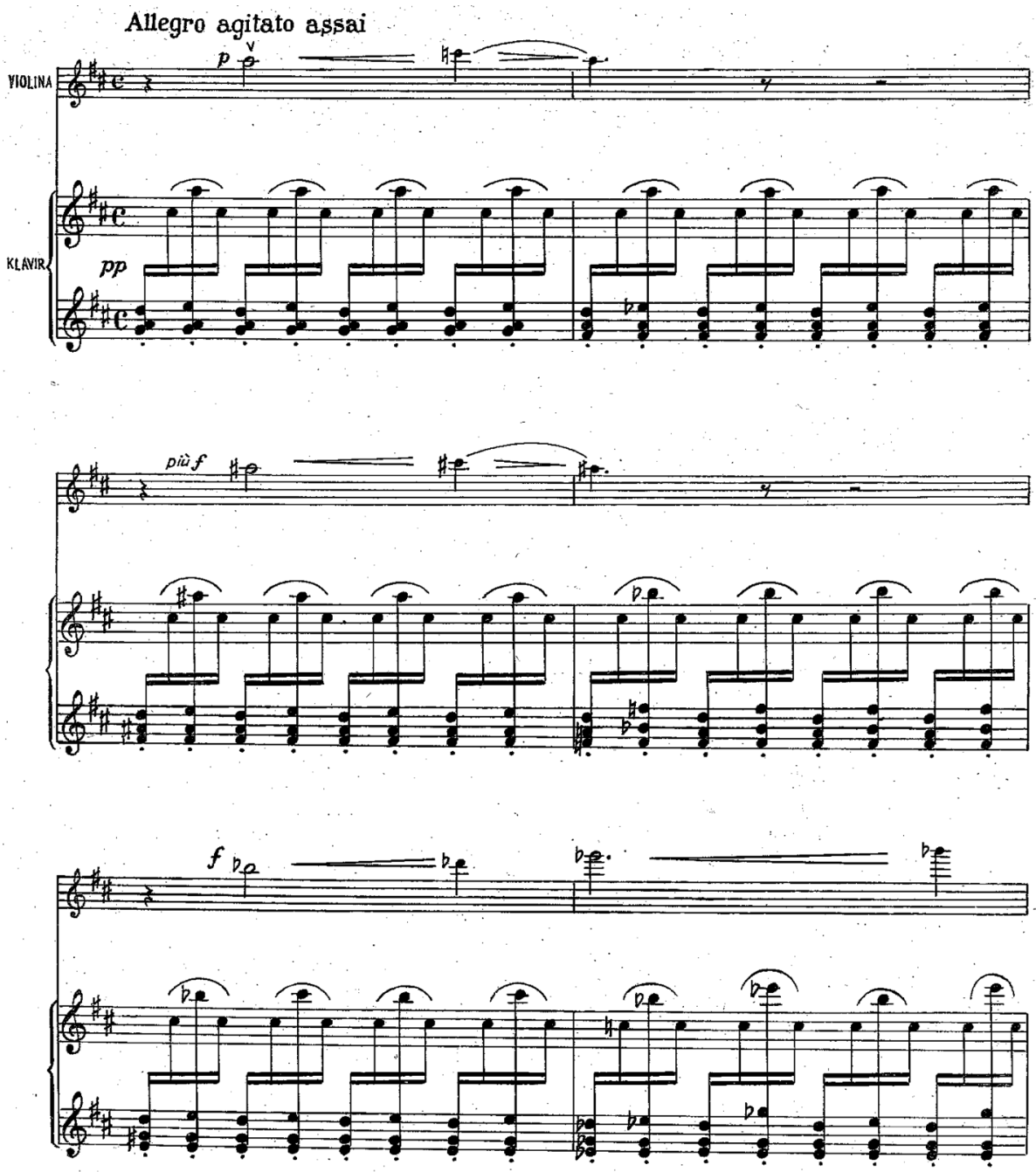

Notni primer I: Začetek Škerjančeve Lirične bagatele. 

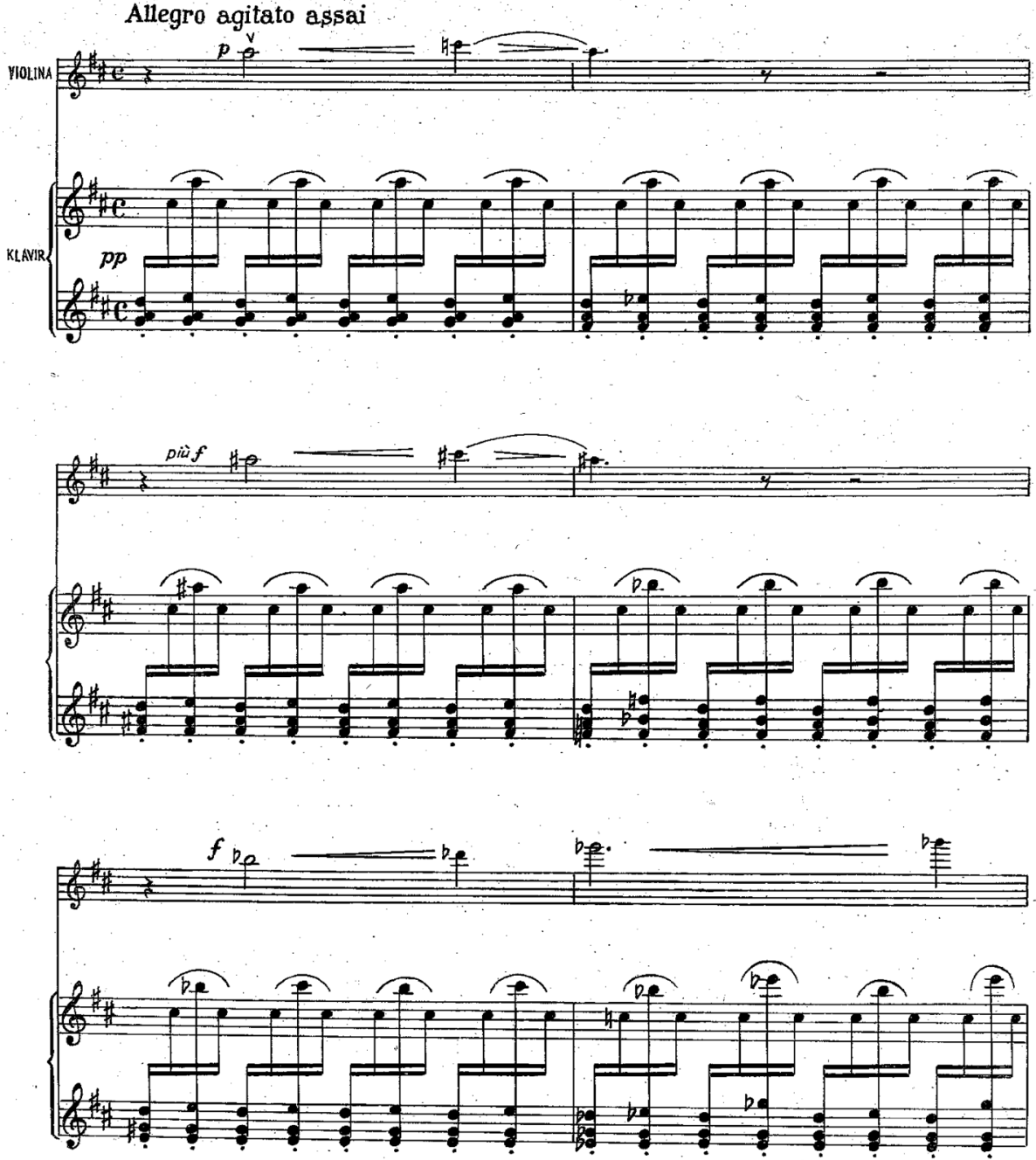

Notni primer 2: Začetek Škerjančeve Lirične bagatele.

pa zaznamujejo tudi odlomek iz prvega in tretjega stavka Koncerta za klavir in pihala (1933).

Osnovno estetsko polarno razmerje med obema skladateljema postaja ob poetoloških sorodnostih zmeraj bolj relativno. Izkaže se, da sta oba skladatelja v svojih estetskih proklamacijah - Osterc se zdi namenoma bojevit in provocira, medtem ko se v svojih zapisih Škerjanc predvsem cinično brani - še radikalna, pa vendar tega njune končne stvaritve ne potrjuje- 
Choral. Lento
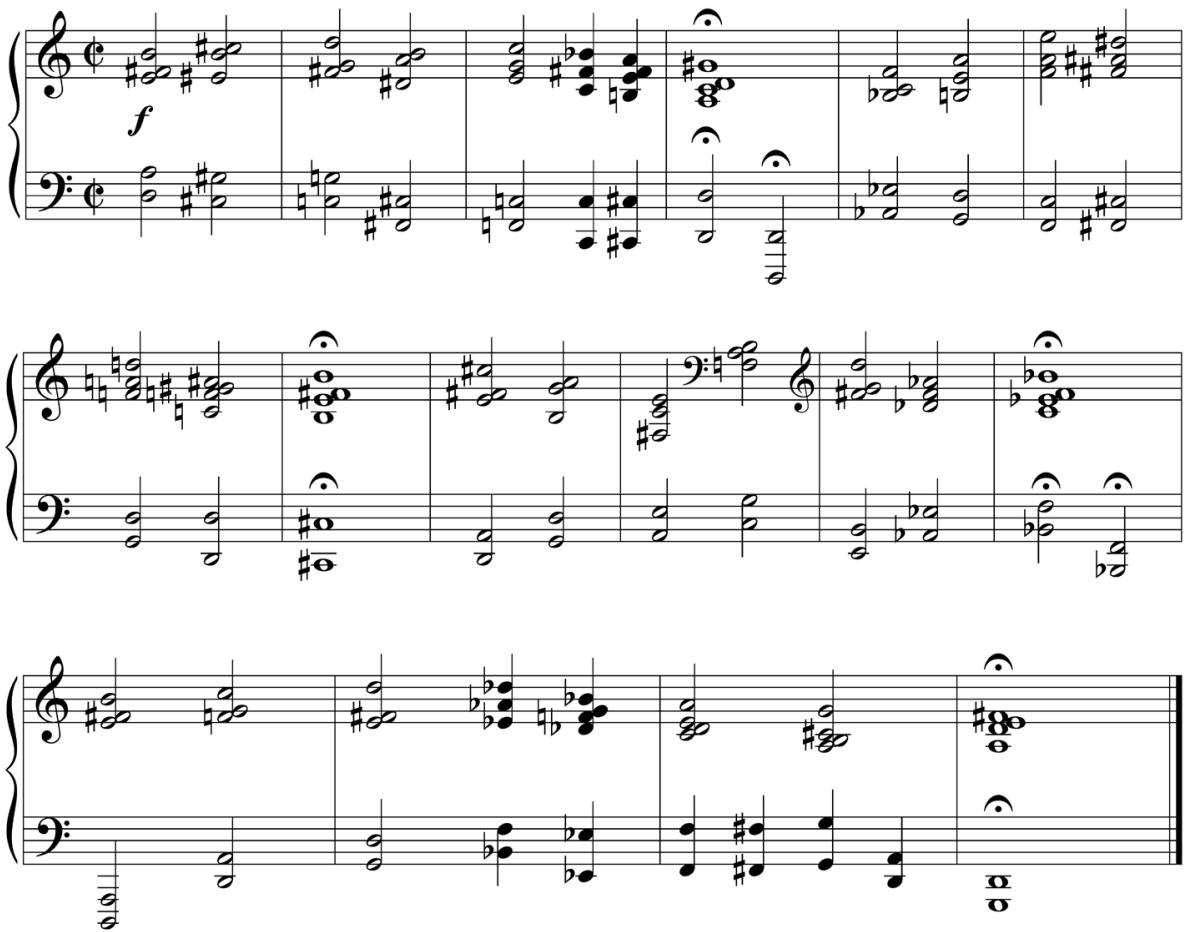

Notni primer 3: Koral iz Osterčevih Štirih miniatur.

jo. Skupaj predstavljata dva pola, morda celo tipa - tradicionalističnega in modernističnega -, toda nobeden ni domišljen povsem dosledno, radikalno in izvirno. Kljub temu pa lahko obema skladateljema pripisujemo odločilno vlogo pri oblikovanju sledečih skladateljskih generacij med obema vojnama, kar kaže predvsem na splošen nivo slovenske glasbe tistega časa, ki je s Škerjancem in Ostercem v prvi vrsti dobila dva tehnično popolnoma verzirana skladatelja. Oba sta svoje okolje, v katerega sta vstopila $\mathrm{z}$ vso močjo konec dvajsetih letih, presegala v obrtniški popolnosti, ki jima je omogočala (pre)hitro ustvarjanje in s tem obsežna opusa, oba sta delovala kot poklicna glasbenika (za generacijo Novih akordov je bilo to še nepredstavljivo) in oba sta se izšolala $v$ tujini, kjer sta prišla $v$ aktivni stik s sodobnimi tokovi, ki pa sta jih prekvasila vsak na svoj način in spremenila v tipološki odnos do tradicionalnega in sodobnega, ki v marsičem zaznamuje slovensko glasbeno ustvarjalnost še danes. Tako lahko imamo Škerjanca in Osterca za dva obraza iste kulture $\mathrm{v}$ isti dobi in ne dva povsem raznorodna pojava, 
ki bi kulturno okolje povsem razdelila: $v$ resnici enega ni brez drugega, kar potrjujejo njuni ambivalentni odnosi. Tako Dragotin Cvetko piše o tem, da nista bila velika prijatelja, a sta se med seboj »umetniško vendarle spoštovala, jasno jima je bilo, kaj kdo od njiju pomeni. Njun odnos je označevala korektnost, ne pa nestrpna napadalnost, $\ll^{38}$ kasneje vendarle tudi prizna, da je bila med Ostercem in Škerjancem "vidna napetost, gotovo zavoljo različnih umetnostnih nazorov ter Škerjančevega nasprotovanja moderni. «" $\mathrm{Za}$ svojo negacijo sodobnega je Škerjanc tako potreboval navidezni protipol, Osterca in njegove učence, temu ustrezno pa je tudi Osterc za svoj boj proti okostenelemu tradicionalizmu potreboval simboličnega sovražnika, ki ga je dobil v Škerjancu. A kot je Škerjanc mestoma dvomil v tradicionalna izhodišča in jih je dopolnjeval s sodobnejšimi impulzi, tako tudi Osterc ni dosledno zaupal zgolj najnovejšim vzpodbudam in $\mathrm{v}$ takem prečiščevalnem relativizmu lahko nedvomno zagledano skupno točko, ki hkrati ne pojasnjuje zgolj razmerja med skladateljema, temveč kaže širšo sliko slovenske glasbe med svetovnima vojnama.

\section{Bibliografija}

Bedina, Katarina. "Nazori Slavka Osterca o tradiciji v glasbi in o glasbenem nacionalizmu«. Muzikološki zbornik 3 (1967): 89-94.

Bedina, Katarina. „K vprašanju o kompozicijskih nazorih Slavka Osterca«. Muzikološki zbornik 4 (1968): 114-119.

Bedina, Katarina. »Novo v mladinskih zborih Slavka Osterca«. Muzikološki zbornik 11 (1975): 93-100.

Bedina, Katarina. »O glasbeni poetiki in prozi Slavka Osterca«. Muzikološki zbornik 25 (1989): 7-14.

Bogunović Hočevar, Katarina. »Ravnikovi glasbenoestetski nazori v kontekstu dveh kompozicijskih šol«. De musica disserenda 6, 2 (2010): 85-99.

Cvetko, Dragotin. Osebnost skladatelja Slavka Osterca. Ljubljana: Cankarjeva založba, 1993.

Kartin, Monika. Simfonije Lucijana Marije Škerjanca, magistrsko delo. Ljubljana: Filozofska fakulteta, 1982.

Kartin, Monika. »Peta simfonija Lucijana Marije Škerjanca«. Muzikološki zbornik 19 (1983): 51-70.

Klemenčič, Ivan. »Slavko Osterc med neoklasicizmom in ekspresionizmom«. Muzikološki zbornik 31 (1995): 11-31.

38 Dragotin Cvetko, Fragment glasbene moderne. Iz pisem Slavku Ostercu (Ljubljana: Slovenska akademija znanosti in umetnosti, 1988), 128. 
Klemenčič, Ivan. Slovenski skladatelji akademiki. Ljubljana: Slovenska akademija znanosti in umetnosti, 2003.

Koter, Darja. Slovenska glasba. 1918-1991. Ljubljana: Študentska založba, 2012. Kreft, Bratko. »Spomini na Slavka Osterca in še marsikaj«. V Varia musicologica 2. Slavko Osterc, ur. Katarina Bedina. Ljubljana: Slovensko muzikološko društvo, 1995, 255-259.

Kuret, Primož. Umetnik in družba. Ljubljana: Državna založba Slovenije, 1988. Lipovšek, Marijan. »Naša glasbena produkcija«. Ljubljanski zvon 55, 10-11 (1935): 573-577.

Osterc, Slavko. »Glavne struje sodobne glasbe in njih eksistenčna upravičenost«. Nova muzika 1 (1928): 2-3.

Osterc, Slavko. »Gledališki pregled. Opera. Matija Bravničar: Pohujšanje v dolini šentflorjanski«. Ljubljanski zvon 50, 6 (1930): 377-378.

Osterc, Slavko. »Muzika u zemlji«. Zvuk 2, 3 (1933): 103-105.

Osterc, Slavko. »Čustvo in razum v glasbi«. Žena 6, 4 (1935): 94-95.

Osterc, Slavko. »Muzika u zemlji. Ljubljana«. Zvuk 3, 6 (1935): 228-230.

Pokorn, Danilo. »Slavko Osterc. Prispevek za biografijo«. Muzikološki zbornik 5 (1969): 83-91.

Rijavec, Andrej. »K vprašanju tonalnosti in vertikale v skladbah Slavka Osterca«. Muzikološki zbornik 6 (1970): 38-53.

Rijavec, Andrej. Kompozicijski stavek komornih instrumentalnih del Slavka Osterca. Ljubljana: Slovenska akademija znanosti in umetnosti, 1972.

Rijavec, Andrej. »Slavko Osterc - an expressionist?«. Muzikološki zbornik 20 (1984): 47-54.

Snoj, Jurij. Portret skladatelja Janeza Matičiča. Ljubljana: Slovenska matica, 2012.

Škerjanc, Lucijan Marija. »Vrednotenja«. Sodobnost 9, 2 (1933): 55-59.

Škerjanc, Lucijan Marija. »Moji umetnostni nazori«. Sodobnost 8, 5 (1940): 203-211.

Škerjanc, Lucijan Marija. »Nezanimivost slovenske glasbe«. Sodobnost 8, 9 (1940): 395-403.

Škerjanc, Lucijan Marija. »Apologia musicae artis«. Sodobnost 1 (1953): $170-182 .^{40}$

40 Poglavje je nastalo kot del projekta J6-7180, ki ga je sofinancirala Agencija za raziskovalno dejavnost Republike Slovenije.

This chapter is part of the project J6-7180 funded by Slovenian research agency ARRS. 